Check for updates

Cite this: RSC Adv., 2020, 10, 18721

Received 10th March 2020

Accepted 29th April 2020

DOI: $10.1039 / \mathrm{d} 0 \mathrm{ra02222e}$

rsc.li/rsc-advances

\section{Structures and photocatalytic properties of two new Zn(II) coordination polymers based on semi- rigid V-shaped multicarboxylate ligands $\uparrow$}

\author{
Shan-He Zhou, ${ }^{a}$ Jun Wang, ${ }^{* a}$ Yi-Wei Liu, ${ }^{b}$ Yuyu Zhong, ${ }^{b}$ Yan-Chun Sun, ${ }^{a}$ Bin Xie, ${ }^{a}$ \\ Aiqing $M a,{ }^{* b}$ Amita Singh, (D) ${ }^{c}$ Mohd. Muddassir ${ }^{d}$ and Abhinav Kumar (D) ${ }^{* c}$
}

\begin{abstract}
Two new metal-organic coordination polymers (CPs), aqua-2,2' -bipyridine-5-(4' -carboxylphenoxy)isophthalatezinc(II) polymer $\left[\mathrm{Zn}(\mathrm{HL})\left(2,2^{\prime} \text {-bipy) }\left(\mathrm{H}_{2} \mathrm{O}\right)\right]_{n}\right.$ (1) and tris-4,4'-bipyridine-bis-5-(4'-carboxylphenoxy)isophthalatetrizinc(II) polymer $\left[\mathrm{Zn}_{3}(\mathrm{~L}) 2\left(4,4^{\prime} \text {-bipy) }\right]_{n}\right.$ (2) $\left(\mathrm{H}_{3} \mathrm{~L}=5\right.$-(4'-carboxylphenoxy)isophthalic acid, 4,4'-bipy $=4,4^{\prime}$ bipyridine and $2,2^{\prime}$-bipy $=2,2^{\prime}$-bipyridine), were obtained under hydrothermal conditions and characterized by microanalysis, FTIR spectroscopy and single crystal X-ray diffraction. The single crystal X-ray diffraction indicated that in both the CPs the coordination networks exhibited varied topologies and coordination modes around the $\mathrm{Zn}(I I)$ centers. CP 1 exhibits a one-dimensional (1D) chain structure, which further forms a 3D supramolecular architecture via intermolecular $\pi \cdots \pi$ and hydrogen bonding interactions, while 2 possesses a 3D framework generated from a 2D layered motif comprising zinc and tripodal carboxylate subunits pillared by 4,4'-bpy ligands. Apart from the structural investigation, the photocatalytic performances of both the coordination polymers to photodecompose an aqueous solution of methyl violet (MV) were examined. The results indicated that both the CPs displayed the potential to photodecompose aromatic dyes and in particular 2 showed good photocatalytic activity for dye degradation under light irradiation. The photocatalytic mechanism through which these CPs executed degradation of dyes has been explained with the assistance of band gap calculations using density of states (DOS) and its decomposed partial DOS calculations.
\end{abstract}

\section{Introduction}

During last couple of years, research dealing with the development of new photocatalysts for the effective degradation of aromatic dyes - lethal contaminants existing in the wastewater discharge - has gained utmost importance. ${ }^{1-3}$ This is because photodegradation is believed to be one of the most promising strategies used for removal of water contamination. ${ }^{1-3}$ This technique can now be considered to be a green ecological technique as it decomposes organic aromatic compounds in waste-water discharge without adding any contaminants to the water, hence forming a basis for sustainable methodology.$^{1-3}$ Although to date a variety of photocatalytic materials have been

${ }^{a}$ School of Chemistry and Environmental Engineering, Sichuan University of Science \& Engineering, Zigong, PR China. E-mail: scwangjun2011@126.com

${ }^{b}$ Dongguan Key Laboratory of Drug Design and Formulation Technology, School of Pharmacy, Guangdong Medical University, Dongguan, 523808, China. E-mail: maqandght@126.com

'Department of Chemistry, Faculty of Science, University of Lucknow, Lucknow, 226007, India. E-mail: abhinavmarshal@gmail.com

${ }^{d}$ Department of Chemistry, College of Sciences, King Saud University, Riyadh 11451, Saudi Arabia

$\dagger$ Electronic supplementary information (ESI) available. CCDC 1981484 and 1981485. For ESI and crystallographic data in CIF or other electronic format see DOI: $10.1039 / \mathrm{d} 0 \mathrm{ra02222 \textrm {e }}$ developed, recently, $\mathrm{CP} / \mathrm{MOF}$ based photocatalysts have been used in the degradation of environmental pollutants. ${ }^{4,5}$ The CPs/MOFs not only find applications as photocatalysts but they also offer application as catalysts in hydrogen evolution and carbon dioxide reduction. ${ }^{4,5}$ In one of the pioneering works, the application of MOF-5 was explored for the photocatalytic degradation of phenol in aqueous medium. ${ }^{6}$ Also, $\mathrm{Zn}_{3}(\mathrm{BTC})_{2}$ film had been studied for the degradation of methylene blue (MB). ${ }^{7}$ The most trustworthy method for the syntheses of the targeted CPs that can find application as photocatalysts is the mixed-ligand synthetic strategy. ${ }^{8}$ In this approach, typical building blocks are bipyridine (which can exist in three positional isomeric forms viz. 2,2'-; 3,3'- and 4,4'-) and polycarboxylate linkers. These are sometimes termed as acid-base mixed-ligand systems. ${ }^{8}$ In comparison to the rigid aromatic polycarboxylate ligands having one phenyl ring as the central molecular framework, the so-called semi-rigid V-shaped multicarboxylate ligands with two phenyl rings bridged by $\mathrm{CH}_{2}$ or $\mathrm{O}$ entity as central molecular framework increases the flexibility of the ligand. These semi-rigid V-shaped multicarboxylate ligands can yield new metal complexes with diversified structures and topological features because of the free rotation of two aromatic rings around the bridged $\mathrm{CH}_{2}$ or $\mathrm{O}$ entity., ${ }^{9,10}$

During last few years we are interested in using V-shaped ligands as flexible and hydrophobic bridging unit for the 


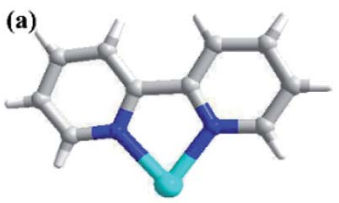

(c)

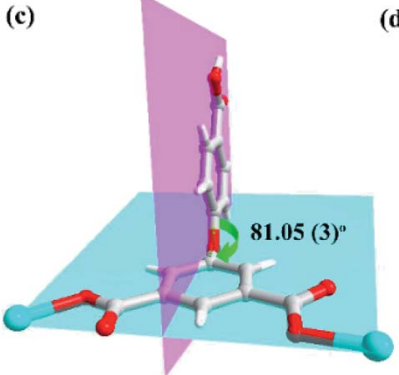

(b)

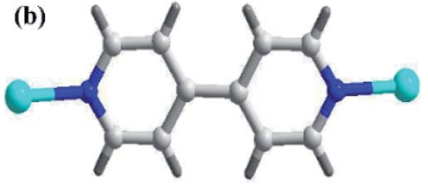

(d)

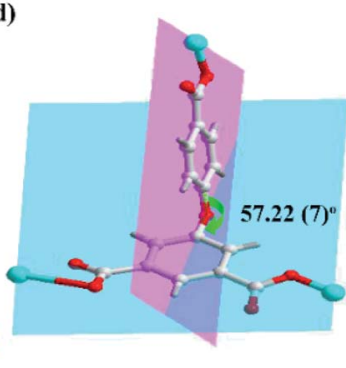

Scheme 1 Bonding modes of (a) 2,2'-bpy and (b) 4,4'-bpy ligand with $\mathrm{Zn}($ II) centers; (c and d) perspective view of the coordination modes of the $\mathrm{V}$-shaped semi-rigid $\mathrm{H} 3 \mathrm{~L}$ ligand and the dihedral angles between the two phenyl rings of H3L ligands in CPs 1 and 2.

development of varied types of CPs/MOFs for different applications. ${ }^{11}$ In order to gain further new information and also to explore the effect of change in the positions of asymmetrically attached carboxylic groups on the molecular structure and functional properties of CPs/MOFs, in the work presented herein, a symmetric semi-rigid V-shaped multicarboxylate ligands 5-(4'-carboxylphenoxy)isophthalic acid $\left(\mathrm{H}_{3} \mathrm{~L}\right)$ (Scheme 1) had been selected to obtain two new coordination polymers with formula $\left[\mathrm{Zn}(\mathrm{HL})\left(2,2^{\prime} \text {-bipy }\right)\left(\mathrm{H}_{2} \mathrm{O}\right)\right]_{n}$ (1) and $\left[\mathrm{Zn}_{3}(\mathrm{~L})_{2}\left(4,4^{\prime}-\right.\right.$ bipy $\left.)_{3}\right]_{n}(2)$ and $\left(\mathrm{H}_{3} \mathrm{~L}=5\right.$-( $4^{\prime}$-carboxylphenoxy)isophthalic acid; $4,4^{\prime}$-bipy $=4,4^{\prime}$-bipyridine and $2,2^{\prime}$-bipy $=2,2^{\prime}$-bipyridine). Also, these CPs have been used as photocatalysts for degrading aqueous solution of methyl violet (MV) which indicated that these newly synthesized CPs can be the promising candidate for visible-light-driven photocatalyst for the degradation of organic pollutants. The results of all these investigations are presented herein.

\section{Experimental}

\section{Materials and method}

All the chemicals and reagents used for the syntheses of both the $\mathrm{Zn}$ (II) based CPs were commercially available and used without further purification. The powder X-ray diffraction (PXRD) data was collected using Bruker ADVANCE X-ray diffractometer with $\mathrm{Cu}-\mathrm{K} \alpha$ radiation $(\lambda=1.5418 \AA)$ at $50 \mathrm{kV}$ voltage, $20 \mathrm{~mA}$ current and scanning rate of $6^{\circ} \mathrm{min}^{-1}$ with step size of $0.02^{\circ}$. Fourier transform infrared (FT-IR) spectra in $\mathrm{KBr}$ discs were recorded using Nicolet Impact 750 FTIR in the range of $400-4000 \mathrm{~cm}^{-1}$.

\section{X-ray crystallography}

The single crystal X-ray diffraction data were collected on Bruker SMART APEX diffractometer equipped with graphite monochromated MoK $\alpha$ radiation $(\lambda=0.71073 \AA)$ by using an $\omega$ - scan technique. The structure of CPs were solved by direct method (SHLEXS-2014) and refined using the full-matrix leastsquares procedure based on $F^{2}$ (Shelxl-2014). ${ }^{12}$ All the hydrogen atoms were generated geometrically and refined isotropically using a riding model. All non-hydrogen atoms were refined with anisotropic displacement parameters. The crystallographic details and selected geometrical parameters for both the CPs are enlisted in Tables S1 and S2, $\uparrow$ respectively. CCDC number: 1981484 and 1981485.

\section{Photocatalytic method}

The finally divided sample of 1 or $2(50 \mathrm{mg}$ ) was added and dispersed in $50 \mathrm{~mL}$ aqueous solution of methyl violet $\left(15 \mathrm{mg} \mathrm{L}^{-1}\right)$. The mixture was stirred under dark for $30 \mathrm{~min}$ to ensure establishment of adsorption-desorption equilibrium. In other word, after being stirred magnetically in dark to achieve adsorption-desorption equilibrium $\left(C_{\mathrm{e}}\right.$ is the adsorptiondesorption equilibrium concentration). Thereafter, the photocatalytic degradation of MV was conducted on XPA-7 type photochemical reactor which was equipped with $100 \mathrm{~W}$ mercury lamp (mean wavelength $365 \mathrm{~nm}$ ) with light intensity of $12.7 \mathrm{~mW}$ $\mathrm{cm}^{-2}$ at quartz tube. During the photocatalytic degradation, aliquots of $5.0 \mathrm{~mL}$ were isolated at specific time intervals and separated through centrifugation and then subsequently the characteristic electronic absorption band of MV was recorded using UV-vis spectrophotometer. Additionally, a control experiment was conducted under the similar reaction conditions but without the addition of CPs $\mathbf{1}$ and 2. The recycle experiments were conducted thrice under the similar reaction conditions. All the data used for analyses are the average value from three times parallel tests.

\section{Computational details}

The possible photocatalytic mechanism with which both the CPs executed the photodegradation of the MV have been explained with the aid of theoretical calculations. The smallest unit of MOF was geometry optimized using the B3LYP functional, ${ }^{13 a, 13 b}$ using $6-31 G^{* *}$ basis set for all the atoms except $\mathrm{Zn}$ for which CEP-121G basis set was employed. All the calculations were performed using Gaussian 09 program, ${ }^{13 c}$ while the density of states and partial density of states for both the compounds were constructed using GaussSum 3.1. ${ }^{13 d}$

\section{Synthesis of 1}

[Zn(HL)(2,2'-bipy)( $\left.\left.\mathrm{H}_{2} \mathrm{O}\right)\right]_{\boldsymbol{n}}$ (1). A mixture of $\mathrm{H}_{3} \mathrm{~L}(0.15 \mathrm{mmol}$, $0.045 \mathrm{~g}), 2,2^{\prime}$-bipy (0.25 mmol, $0.048 \mathrm{~g}$ ) and $\mathrm{Zn}\left(\mathrm{NO}_{3}\right)_{2} \cdot 6 \mathrm{H}_{2} \mathrm{O}$ $(0.40 \mathrm{mmol}, 0.119 \mathrm{~g}$ ) was taken in $10 \mathrm{~mL}$ distilled water and $\mathrm{pH}$ value was adjusted to 6.0 with $0.5 \mathrm{~mol} \mathrm{~L}^{-1} \mathrm{NaOH}$ aqueous solution. Thereafter, the mixture was transferred in a Teflonlined stainless steel vessel $(25 \mathrm{~mL})$, and heated to $180{ }^{\circ} \mathrm{C}$ for $72 \mathrm{~h}$ and then cooled to room temperature at a rate of $5{ }^{\circ} \mathrm{C} \mathrm{h}^{-1}$. Colourless block crystals of 1 were obtained in $66 \%$ yield based on zinc. Anal. calcd for 1 (\%): C, 55.63; H, $3.36 \mathrm{~N}, 5.19$. Found: C, 55.42; H, 3.39; N, 5.23. IR (KBr, $\left.\mathrm{cm}^{-1}\right)$ : 3191(v), 2348(w), 1712(v), 1627(m), 1570(m), 1442(s), 1299(m), 1087(m), 973(m), 767(s). 
$\left[\mathbf{Z n}_{3}(\mathbf{L})_{2}\left(\mathbf{4}, \mathbf{4}^{\prime} \text {-bipy }\right)_{3}\right]_{n}$ (2). The synthesis procedure of 2 was analogous to that of 1 , except that $2,2^{\prime}$-bipy was replaced by $4,4^{\prime}$ bipy $(0.25 \mathrm{mmol}, 0.048 \mathrm{~g})$. Colorless block crystals of 2 were obtained in $62 \%$ yield based on zinc. Anal. calcd for 2 (\%): C, 57.05; H, 3.03; N, 6.65. Found: C, 56.87; H, 3.06; N, 6.71. IR $\left(\mathrm{KBr}, \mathrm{cm}^{-1}\right)$ : 3382(v), 2928(w), 1613(m), 1549(m), 1435(m), 1364(s), 1108(m), 930(s), 774(m), 724(m).

\section{Results and discussion}

\section{Molecular structure description of $\left[\mathrm{Zn}(\mathrm{HL})\left(2,2^{\prime}-\mathrm{bipy}\right)\left(\mathrm{H}_{2} \mathrm{O}\right)\right]_{n}$} (1)

In the CP 1, the asymmetric unit comprises a Zn1 center, a $\mu_{2}$ $\mathrm{HL}^{2-}$ linker, one coordinated water and 2,2'-bipy (Fig. 1a). The penta-coordinate $\mathrm{Zn} 1$ displays trigonal bipyramid geometry $\left\{\mathrm{ZnN}_{2} \mathrm{O}_{3}\right\}$, where the coordination positions are occupied by two O-donors from two $\mu_{2}-\mathrm{HL}^{2-}$ blocks, one $\mathrm{O}$ center from water molecule and a pair of $\mathrm{N}$ from 2,2'-bipy donors. The $\mathrm{Zn}-\mathrm{O}$ bond lengths vary between 2.0287(18)-2.591(4) $\AA$, while $\mathrm{Zn}-\mathrm{N}$ bond lengths lies between 2.109(2)-2.1134(18) A. These bonding parameters are in good agreement with previously reported $\mathrm{Zn}$ (II) based analogous compounds. ${ }^{14}$ The ligand $\mathrm{HL}^{2-}$ behaves as a $\mu_{2}$-linker (Scheme 1) with two $\mathrm{COO}^{-}$groups displaying monodentate-bridging modes while the third $\mathrm{COOH}$ functionality remains uncoordinated. In $\mathrm{HL}^{2-}$, the dihedral angles between two aromatic rings and a $\mathrm{C}-\mathrm{O}$ ether- $\mathrm{C}$ angle are 81.05(3) and $122.23(4)^{\circ}$, respectively. The $\mathrm{HL}^{2-}$ blocks connect the $\mathrm{Zn} 1$ centres to generate a $1 \mathrm{D}$ zigzag chain structure with the Zn1‥Zn1 separation of 9.926(8) A (Fig. 1c). Also, these chains are connected together by the $\mathrm{O}-\mathrm{H} \cdots \mathrm{O}$ hydrogen bonds to form a 2D supramolecular network (Fig. 1b). These layers are further packed into a 3D supramolecular network via intermolecular $\pi-$ $\pi$ interaction (face-face distance amounting to 3.682(4) $\AA$ ) between 2,2'-bipy ligands of neighbouring layers (Fig. 1c and d). ${ }^{8,15}$

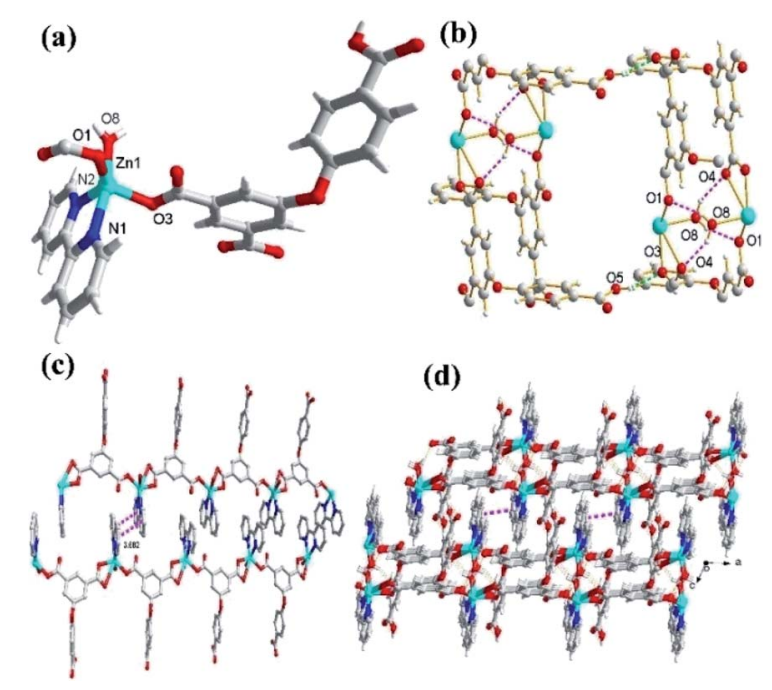

Fig. 1 (a) The coordination environment around $\mathrm{Zn}(\mathrm{II})$ ion in 1. (b) Perspective view of $2 \mathrm{D}$ network in 1 . (c) The $2 \mathrm{D}$ supramolecular networks through intermolecular $\pi-\pi$ interaction. (d) View of 3D supramolecular frameworks in complex 1.
Molecular structure description of $\left[\operatorname{Zn}_{3}(\mathrm{~L})_{2}\left(4,4^{\prime} \text {-bipy }\right)_{3}\right]_{n}(2)$

Unlike 1, the CP 2 was obtained by introducing linear $\mathrm{N}$-donor (4,4'-bipy) secondary ligand instead of the chelating $\mathrm{N}$-donor (2,2'-bipy) ligand, which has a complicated 3D frame as expected. In 2 , the geometry around the $\mathrm{Zn}$ (II) centers are tetrahedral which are satisfied by two oxygen centers from two $\mathrm{L}^{3-}$ ligands in trans configuration and two $\mathrm{N}$ atoms from $4,4^{\prime}$-bpy ligands (Fig. 2a-c). Unlike 1, in 2 all the $\mathrm{H}_{3} \mathrm{~L}$ ligand is completely deprotonated and the $\mathrm{L}^{3-}$ moiety acts as a $\mu_{3}$-linker (Scheme $1 \mathrm{~b}$ and $\mathrm{d}$ ) where all the $\mathrm{COO}^{-}$groups adopt $\mu$-bridging monodentate coordination modes. Besides this, the $\mathrm{L}^{3-}$ is considerably bent showing a dihedral angles of $57.22(7)^{\circ}$ and $123.46(2)^{\circ}$ between two aromatic rings and the $\mathrm{C}-\mathrm{O}$ ether- $\mathrm{C}$ units. The neighbouring zinc subunits are linked by 4-carboxylic groups in syn-anti coordination mode to form a 1D chain. The adjacent chains are further connected by the $\mathrm{L}^{3-}$ ligands to give rise a $2 \mathrm{D}$ covalent network. The 4,4'-bipy ligands connect the $\mathrm{Zn}$ (II) ions of neighbouring 2D layered networks as pillar to form a $3 \mathrm{D}$ structure (Fig. 2d). ${ }^{8}$ The topological analysis was performed using the concept of the underlying net. After a simplification procedure, an underlying net has been obtained (Fig. S1 $\dagger$ ). This framework can be defined as a 4-connected net with the point symbol of $\left(4^{2} \cdot 6^{3} \cdot 8\right)$, by denoting both the $\mathrm{Zn}$ (II) centers as fourconnected nodes.

In the presented investigation both the CPs were synthesized by one-pot reaction and afforded different structures and these structures were influenced by the variation in $\mathrm{N}$-donor ligands. The dihedral angles between the two phenyl rings of $\mathrm{H}_{3} \mathrm{~L}$ ligands are shown in Scheme 1. In $\mathbf{1}$, the $\mathrm{HL}^{2-}$ ligand connects two adjacent $\mathrm{Zn}$ centers to form a single-stranded chain. However, in 2, there are two types of carboxylate chains which were influenced by the flexibility of $\mathrm{H}_{3} \mathrm{~L}$. Meanwhile, the completely deprotonated $\mathrm{L}^{3-}$ ligand connects two adjacent $\mathrm{Zn}$ centers to generate a layer with different dihedral angles. In other words, in these CPs obtained from mixed ligands, the difference in their molecular structures indicate the significant

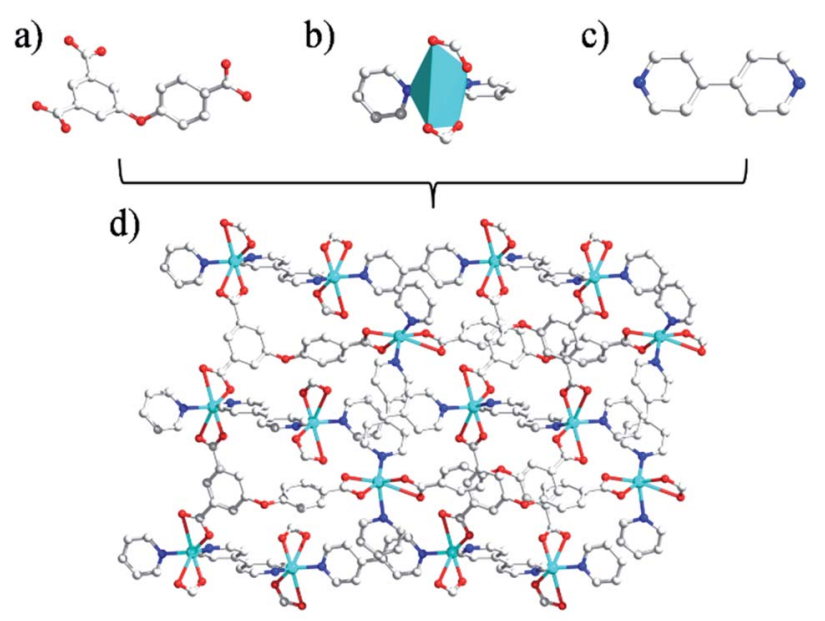

Fig. 2 ( $a$ and c) The linkers built by coligand; (b) the diagram of coordination geometry for $\mathrm{Zn}(\Perp)$ atoms in 2 (the 30\% probability level), all hydrogen atoms and water molecules have been omitted for clarity; (d) 3D network pillared by 4,4'-bpy ligands. 
spacer effect of secondary $\mathrm{N}$-donor ligands which is modulating the molecular structures of coordination polymers as well as the bridging modes and conformations of $\mathrm{H}_{3} \mathrm{~L}$ ligand. ${ }^{8}$

\section{IR, SEM and UV-vis diffuse reflectance spectroscopy (DRS)}

In the FTIR spectra, the bands at $\sim 3400 \mathrm{~cm}^{-1}$ arises due to the aqua ligand in 1 . The characteristic bands at $1400-1580 \mathrm{~cm}^{-1}$ can mainly be attributed to asymmetric and symmetric stretching vibrations of the carboxylato groups. The $\Delta \nu\left[\nu_{\text {as }}(-\right.$ COO $\left.)-\nu_{\mathrm{s}}(\mathrm{COO})\right]$ values of 211 and $188 \mathrm{~cm}^{-1}$ for 1 and 2 , respectively indicates coordination modes of carboxylato groups to the metal centres (Fig. $\mathrm{S} 2 \dagger$ ). The band observed at $c a$. $1506 \mathrm{~cm}^{-1}$ in both 1 and 2 can be assigned to $\nu(\mathrm{C}=\mathrm{N})$ absorption of the N-donor ligand. In SEM, the morphologies and particle sizes of both the CPs can be viewed. The as-synthesized 1 and 2 consist of collapsed octahedron crystals with a nonuniform diameter $c a .700 \mathrm{~nm}$ (Fig. S3†). The UV-vis diffuse reflectance spectra of the CPs in the range of 200-800 nm was measured with $\mathrm{BaSO}_{4}$ as a reference (Fig. S4 $\dagger$ ). The absorption spectra revealed that $\mathbf{1}$ and $\mathbf{2}$ have an absorption edge around $237 \mathrm{~nm}$. In addition, another absorption band in the region of 250-600 $\mathrm{nm}$ for 1 and 2 can be observed. Therefore, 1 and 2 have electronic absorption in the visible range of the spectrum. The band gaps calculated using the Tauc plot were found to be $2.62 \mathrm{eV}$ and $2.93 \mathrm{eV}$ for $\mathbf{1}$ and 2 , respectively which is an important parameter for evaluating light utilization (Fig. S4†). ${ }^{15 b}$

\section{Photocatalysis property}

In this study, both the CPs have been used as photocatalyst for the safe and sustainable photodecomposition of the model aromatic dye methyl violet (MV) a contaminant generally existing in wastewater. The extent of degradation of MV in presence of both the CPs as photocatalysts were monitored by recording the characteristic absorption band of MV at $580 \mathrm{~nm}$ (Fig. 3a and b). The variation in the UV-vis absorption intensity related to the concentrations of $\mathrm{MV}$ solutions $\left(C_{t} / C_{0}\right)$ against the irradiation time in presence of photocatalysts were also plotted (Fig. 3c). About $64.82 \%$ and $78.18 \%$ of MV underwent photodegradation after $40 \mathrm{~min}$ on UV-vis irradiation in the presence of $\mathbf{1}$ and 2, respectively (Fig. 3c), while merely $18.66 \%$ photodegradation of MV was recorded under the control conditions in the absence of CPs. Therefore, the experiments indicate that CPs 1 and 2 can be used as efficient catalysts for the photocatalytic degradation of MV.

To gain better understanding of the reaction kinetics of MV photodegradation, the experimental data were fitted to the firstorder model using Langmuir-Hinshelwood model. The $k$ value is the rate constant which had been obtained from the slope and the intercept of the linear plot. ${ }^{16}$ For CPS 1 and 2, the photodegradation rate constants values are $0.02705 \mathrm{~min}^{-1}$ and $0.03260 \mathrm{~min}^{-1}$, respectively.

The photocatalytic properties of both the CPs reported herein have been compared to some previously reported CPs/ MOFs which displayed photocatalytic properties (Table 1) ${ }^{\mathbf{1 7}}$ which suggests that CPs reported herein offered good
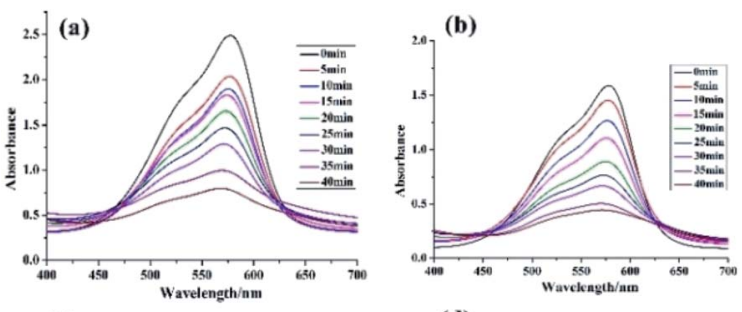

(c)

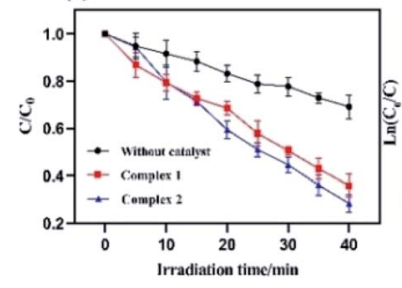

(d)

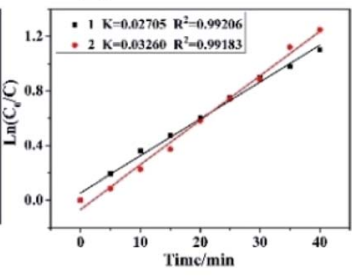

Fig. 3 ( $a$ and $b$ ) the electronic absorption spectra of the MV solutions during the decomposition reaction under UV irradiation in the presence of 1 and 2, respectively; (c) over different catalysts, and the rate constant $k$ for degradation of $\mathrm{MV}$; (d) linear-log plot as a function of visible light irradiation time in the presence of 1 and 2 .

application as the photocatalyst for the decomposition of the MV and in certain experimental aspects they are advantageous. ${ }^{17}$ In addition to these reports, a MOF-based photocatalyst ZnO@ZIF-8 had been reported which requires more energy by using UV light ( $300 \mathrm{~W}$ high pressure $\mathrm{Hg}$ lamp) than the CPs 1 and 2 (100 W high pressure $\mathrm{Hg}$ lamp). ${ }^{18}$ Also, the amount of these CPs required during photocatalysis is less than our previously reported photocatalyst $(80 \mathrm{mg}) .{ }^{19}$ Despite, smaller dosage the CPs 1 and $\mathbf{2}$ displayed better photodegradation properties under similar condition. ${ }^{19}$

To investigate the plausible photocatalytic degradation reaction mechanism and to assess the nature of apposite reactive species which may primarily be responsible for the decomposition of $\mathbf{M V},{ }^{\mathbf{2 0}-22}$ the photodegradation of $\mathrm{MV}$ was carried out in the presence of three different quenchers viz. tertiary butyl alcohol (TBA) a $\cdot \mathrm{OH}$ radical quencher, benzoquinone (BQ) a $\mathrm{O}_{2}{ }^{\cdot-}$ radical quencher and ammonium oxalate (AO)

Table 1 Performances of some photocatalysts for the degradation of MV

\begin{tabular}{llll}
\hline Compounds & Irradiation & $\begin{array}{l}\text { Degradation } \\
\text { efficiency }(\%)\end{array}$ & Ref. \\
\hline$\left[\mathrm{Zn}_{7}(\mathrm{NDC})_{5.5}\left(\mu_{4}-\mathrm{OH}\right)_{3}\right]$ & $\mathrm{UV}$ & 65 & $17 a$ \\
{$\left[\mathrm{Zn}_{2}(\mathrm{pa})_{2}(\mathrm{bip})_{2}\right]$} & $\mathrm{UV}$ & 52 & $17 b$ \\
{$\left[\mathrm{Zn}_{4}\left(\mu_{2}-\mathrm{OH}\right)_{2}(\mathrm{BDC})_{3}(\mathrm{bip})_{2}\right]$} & $\mathrm{UV}$ & 82 & $17 c$ \\
{$\left[\mathrm{Zn}_{2}(\mathrm{fer})_{2}\right]$} & $\mathrm{UV}$ & 54 & $17 d$ \\
{$\left[\mathrm{Zn}_{3}(\mathrm{btc})_{2}(\mathrm{bimmb})_{2.5}\right]$} & $\mathrm{UV}$ & 92.16 & $17 e$ \\
$\mathrm{Bi}_{6} \mathrm{O}_{6}(\mathrm{OH})_{2}\left(\mathrm{NO}_{3}\right)$ & $\mathrm{UV}$ & 93 & $17 f$ \\
$\mathrm{CuO}$ nanoleaves & UV & 96 & $17 g$ \\
$\mathrm{BFO} / \mathrm{RGO}$ composites & UV & 65.1 & $17 h$ \\
{$\left[\mathrm{Zn}\left(\mathrm{SO}_{4}\right)_{3}(\mathrm{DMF})_{3}\right]$} & $\mathrm{UV}$ & 76 & $17 i$ \\
$\mathrm{Zn}\left(\mathrm{C}_{40} \mathrm{H}_{3} 6 \mathrm{~N}_{4} \mathrm{O}_{8}\right)$ & $\mathrm{UV}$ & 45 & $17 j$ \\
{$\left[\mathrm{Co}\left(\mathrm{H}_{2} \mathrm{ODPT}\right)(\mathrm{bpe})\left(\mathrm{H}_{2} \mathrm{O}\right)\right]$} & $\mathrm{UV}$ & 32 & $17 k$ \\
{$[\mathrm{Zn}(\mathrm{tmlb})(\mathrm{bbibp})]_{n}$} & UV & 97.3 & $17 l$ \\
1 & UV-vis & 75 & This work \\
2 & UV-vis & 65 & This work
\end{tabular}


which act as $\mathrm{h}^{+}$radicals quenchers (Fig. 4a and 5a). The photocatalytic reactions executed in presence of these quenchers indicated that TBA dropped the photodegradation of MV in the presence of both the CPs (Fig. 4b, c, 5b and c) (Table 2).

Additionally it is apparent that the rate constants for the decomposition of MV in presence of CPs observed to decrease from 0.02705 to $0.01457 \mathrm{~min}^{-1}$ for 1 and 0.03260 to $0.01723 \mathrm{~min}^{-1}$ for 2 in the presence of TBA under UV-vis irradiation. Therefore, the photodegradation of MV in presence of - $\mathrm{OH}$ quencher suggest that the photodegradation of MV by the CPs used as photocatalysts is dominated by $\cdot \mathrm{OH}$ radical group. ${ }^{20}$ The exact mechanism in presence of each of these catalysts is challenging and deserves special attention in a future work. ${ }^{23}$ Furthermore, after photocatalysis experiments, the CPs were filtered and characterized using PXRD (Fig. S5 and $\mathrm{S} 6 \dagger)$. The results indicated that CPs isolated after photodegradation experiments displayed nearly identical PXRD pattern as can be obtained for pristine CPs. The PXRD results provides evidence that the CPs are stable enough to be used as photocatalysts to initiate the fresh catalytic cycles. On the basis of this information, the repeated photocatalytic degradation of MV was explored which indicated that the photodegradation rates of MV in presence of $\mathbf{1}$ and $\mathbf{2}$ displayed no significant decline even when the photocatalyst was used five times in under similar reaction conditions. Thus, the recycling experiments indicated that both of the CP based materials were stable and can be used as photocatalysts for degradation of MV for atleast four cycles (Fig. $4 \mathrm{~d}$ and $5 \mathrm{~d}$ ).

To establish the plausible mechanism with the aid of which both the CPs executed photo-degradation of MV, the band structure calculations were performed which was based on density functional theory (vide supra). Using DFT calculations, the DOS and partial DOS plots have been constructed (Fig. 6). The plots display that the valence band in both the CPs are having major contributions from aromatic carbons and carboxylate oxygens. Additionally in case of 2 nitrogen centers

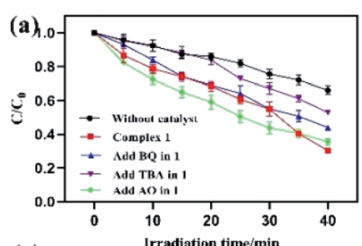

(c)

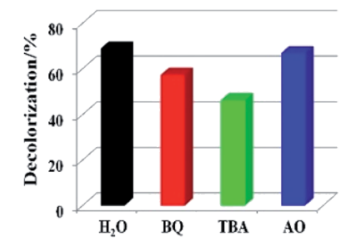

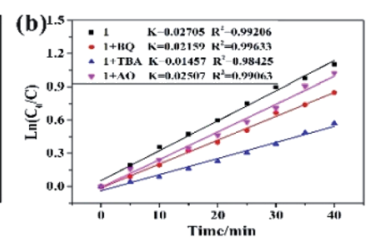

(d)

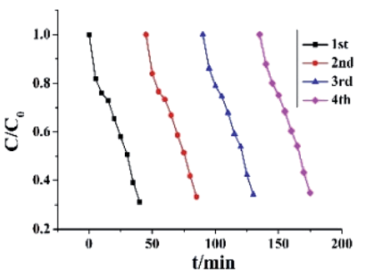

Fig. 4 (a) Photocatalytic decomposition of MV solution under UV-vis light irradiation with the use of 1 and different scavenger solutions; (b) linear-log plot as a function of visible light irradiation time in the presence of 1 and different scavengers; (c) photodegradation of the MV solution over 1 in the different scavenger solutions; (d) cycling four runs of the photocatalytic degradation of MV for 1 .
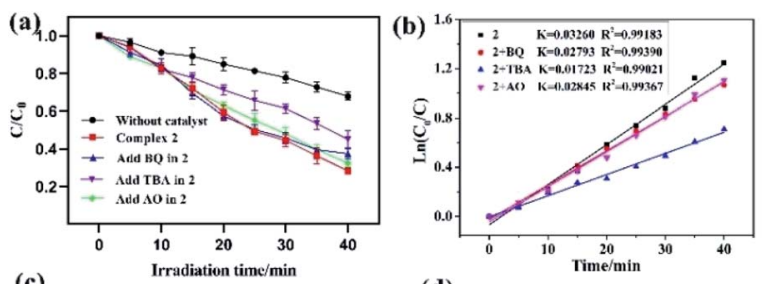

(c)

(d)
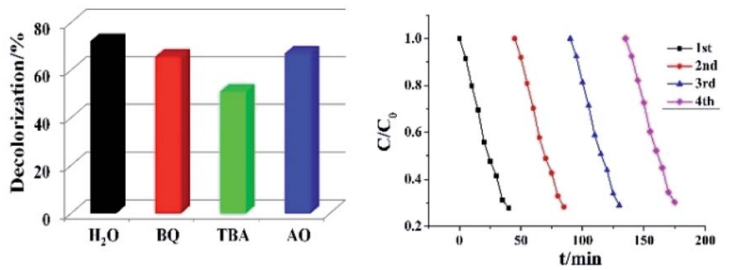

Fig. 5 (a) Evolution of the MV concentration under solar irradiation with the different scavenger solutions; (b) linear-log plot as a function of visible light irradiation time in the presence of 2 and different scavengers; (c) photodegradation of the MV solution over 2 in the different scavenger solutions; (d) cycling four runs of the photocatalytic degradation of MV for 2.

of 4,4'-bipy ligand is also having contribution in the valence band. However, in both the compounds $\mathrm{Zn}$ (II) centers are offering negligible contribution. Also, the conduction band in both the CPs are having contributions from aromatic carbon and nitrogen centers. Therefore, pDOS plots suggest that in both the CPs electronic transitions are of ligand-to-ligand type. The most probable reason for the observed differences in the photocatalytic performances of CPs may be the band gap differences. Apart from this, in the case of 2, the 4,4'-bipy is acting as a linker and is also contributing in the valence band of the 2 and therefore is not only playing a critical role in formation of framework rather also tuning the electronic communication in 2 . This may be also be the another reason for relatively superior photocatalytic performance of $\mathbf{2}$ in comparison to $\mathbf{1}$.

Therefore, it can be inferred from the integrated experimental and theoretical calculations that charge transfer operates from valence band $(\mathrm{VB}) \rightarrow$ conduction band (CB) in photoexcited CPs which in turn generates a hole in VB. To revert back to its stable state the $\mathrm{CB}$ captures an electron from water molecule which itself gets converted to $\mathrm{HO}^{\circ}$ radical which is an active species. The generated $\mathrm{HO}^{\circ}$ radicals then decomposes the MV to accomplish the photocatalytic process. The mechanistic

Table 2 Parameters of photodegradation reactions of MV in 1 and 2

\begin{tabular}{lll}
\hline & \multicolumn{2}{l}{$\mathrm{MV}$} \\
\cline { 2 - 3 } Materials & $k\left(\mathrm{~min}^{-1}\right)$ & $R^{2}$ \\
\hline $\mathbf{1}+\mathrm{BQ}$ & 0.02705 & 0.99206 \\
$\mathbf{1}+\mathrm{TBA}$ & 0.02159 & 0.99633 \\
$\mathbf{1}+\mathrm{AO}$ & 0.01457 & 0.98425 \\
$\mathbf{2}$ & 0.02507 & 0.99063 \\
$\mathbf{2}+\mathrm{BQ}$ & 0.03260 & 0.99183 \\
$\mathbf{2}+\mathrm{TBA}$ & 0.02793 & 0.99390 \\
$\mathbf{2}+\mathrm{AO}$ & 0.01723 & 0.99021 \\
& 0.02845 & 0.99367
\end{tabular}




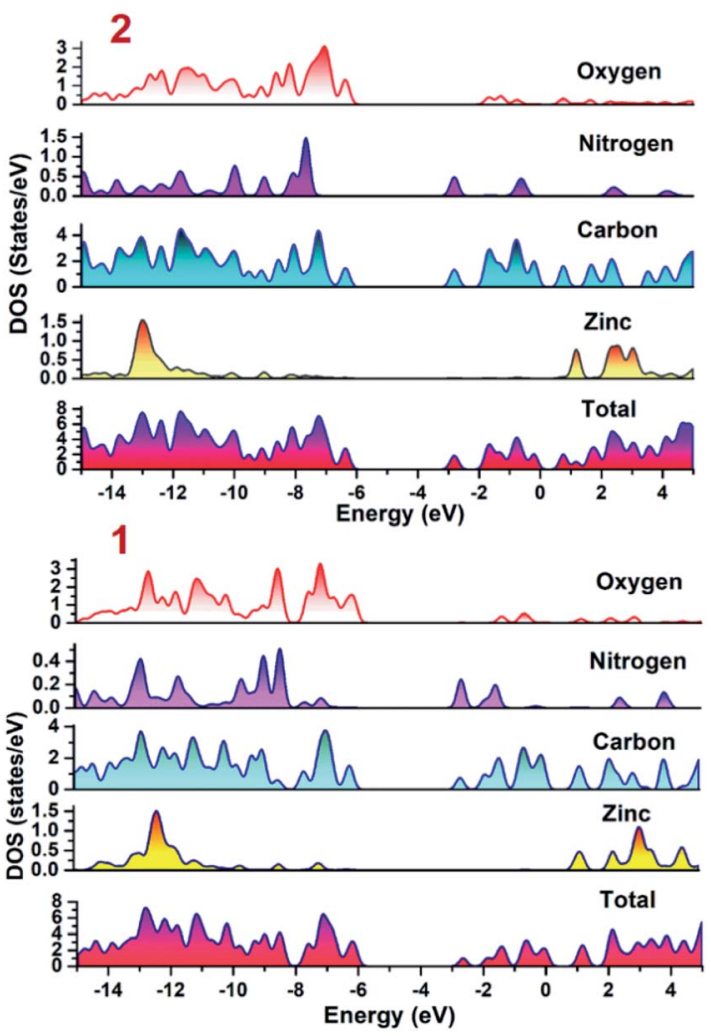

Fig. 6 Density of states (DOS) and partials DOS plots for 1 and 2.

pathway through which the entire photocatalysis is operating can be presented as: ${ }^{\mathbf{1 1}, \mathbf{1 2}}$

$$
\begin{gathered}
\mathrm{CP} \stackrel{h \nu}{\rightarrow} \mathrm{CP}^{*} \text { i.e. } \mathrm{CP}\left(\mathrm{h}^{+}+\mathrm{e}^{-}\right) \\
\mathrm{CP}\left(\mathrm{h}^{+}+\mathrm{e}^{-}\right)+\mathrm{H}_{2} \mathrm{O} \rightarrow \mathrm{CP}\left(\mathrm{e}^{-}\right)+\mathrm{HO}^{*}+\mathrm{H}^{+} \\
\mathrm{HO}^{\cdot}+\mathrm{MV} \rightarrow \text { oxidation products } \rightarrow \mathrm{CO}_{2}+\mathrm{H}_{2} \mathrm{O} \\
\mathrm{CP}\left(\mathrm{e}^{-}\right)+\mathrm{O}_{2} \rightarrow \mathrm{CP}\left(\mathrm{O}_{2}^{\cdot-}\right) \\
\mathrm{O}_{2}^{\cdot-} / \mathrm{HO}_{2}^{\cdot}+\mathrm{S} \rightarrow \text { oxidation products }
\end{gathered}
$$

\section{Conclusion}

Two new Zn(II) based CPs have been synthesized using semirigid V-shaped 5-(4'-carboxylphenoxy)isophthalic acid as ligand while $2,2^{\prime}$-bipy and 4,4'-bipy as co-ligands. These newly synthesized CPs possess entirely different topologies and been used as the photocatalysts for the photodecomposition of methyl violet and offered differences in their photocatalytic performances. The variation in photocatalytic performances in these CPs may be arising because of the differences in band gaps as well as the presence of 4,4'-bipy in one of the CP which led to the enhancement in the electron and hole transfer process. In conclusion, the selection of appropriate linker can generate the desirable framework and in turn can fine tune the electron and hole transfer properties in the resulting CPs. These variations in the topologies and electron transfer properties could be utilized to decipher photocatalytic properties in the targeted CPs.

\section{Conflicts of interest}

There are no conflicts to declare.

\section{Acknowledgements}

The authors acknowledge financial assistance from Sichuan University of Science and Engineering (no. 2015RC29 and 2019RC21), and the Project of Zigong Science \&Technology (No. 2018YYJC01 and 2019YYJC06). Authors are also grateful to Researchers Supporting Project (RSP-2019/141), King Saud University, Riyadh, Saudi Arabia for financial assistance.

\section{References}

1 D. E Wang, K. J. Deng, K. L. Lv, C. G. Wang, L. L. Wen and D. F. Li, CrystEngComm, 2009, 11, 1442-1450.

2 J. Ding, Z. Q. Yang, C. He, X. W. Tong, Y. Li, X. J. Niu and H. G. Zhang, J. Colloid Interface Sci., 2017, 497, 126-133.

3 X. D. Zhang, Y. Yang, W. Y. Huang, Y. Q. Yang, Y. X. Wang, C. He, N. Liu, M. H. Wu and L. Tang, Mater. Res. Bull., 2018, 99, 349-358.

4 (a) Z. Sha, H. S. O. Chan and J. S. Wu, J. Hazard. Mater., 2015, 299, 132-140; (b) L. L. Liu, C. X. Yu, J. Sun, P. P. Meng, F. J. Ma, J. M. Du and L. F. Ma, Dalton Trans., 2014, 43, 2915-2924.

5 L. L. Liu, C. X. Yu, Y. R. Li, J. J. Han, F. J. Ma and L. F. Ma, CrystEngComm, 2015, 17, 653-664.

6 M. Alvaro, E. Carbonell, B. Ferrer, F. X. LlabrésiXamena and H. Garcia, Chem.-Eur. J., 2007, 13, 5106-5112.

7 Z. Q. Li, M. Zhang, B. Liu, C. Y. Guo and M. Zhou, Inorg. Chem. Commun., 2013, 36, 241-244.

8 H. L. Wang, K. Wang, D. F. Sun, Z. H. Ni and J. Z. Jiang, CrystEngComm, 2011, 13, 279-286.

9 (a) M. Eddaoudi, J. Kim, N. Rosi, D. Vodak, J. Wachter, M. O'Keefeand and O. M. Yaghi, Science, 2002, 295, 469472; (b) L. L. Liu, C. X. Yu, J. M. Du, S. M. Liu, J. S. Cao and L. F. Ma, Dalton Trans., 2016, 45, 12352-12361.

10 (a) L. L. Liu, C. X. Yu, F. J. Ma, Y. R. Li, J. J. Han, L. Lin and L. F. Ma, Dalton Trans., 2015, 44, 1636-1645; (b) D. R. Xiao, E. B. Wang, H. Y. An, Y. G. Li, Z. M. Su and C. Y. Sun, Chem.-Eur. J., 2006, 12, 6528-6541; (c) F. Xun, L. X. L. Ling, L. Liu, H. L. Song, S. W. Ng and B. T. Su, Dalton Trans., 2013, 42, 10292-10303; (d) X. Feng, Y. Q. Feng, L. Liu, H. L. Song and S. W. Ng, Dalton Trans., 2013, 42, 7741-7754. 11 (a) J. Wang, X. R. Wu, J. Q. Liu, B. H. Li, A. Singh, A. Kumar and S. R. Batten, CrystEngComm, 2017, 19, 3519-3525; (b) J. Wang, C. Bai, H. M. Hu, F. Yuan and G. L. Xue, J. Solid State Chem., 2017, 249, 87-97; (c) L. Lu, J. Wang, B. Xie, J. Q. Liu, R. Yadav, A. Singh and A. Kumar, New J. Chem., 2017, 41, 3537-3542; (d) Y. Wu, Y. L. Li, X. R. Wu, M. M. Luo, L. K. Zou, Q. X. Xu and S. G. Cai, J. Solid State Chem., 2018, 262, 256-263; (e) A. Q. Ma, J. Wu, Y. T. Han, 
F. M. Chen, B. H. Li, S. G. Cai, H. Huang, A. Singh, A. Kumar and J. Q. Liu, Dalton Trans., 2018, 47, 9627-9633.

12 G. M. Sheldrick, Acta Crystallogr., Sect. A: Found. Adv., 2015, 7, 3-8.

13 (a) A. D. Becke, J. Chem. Phys., 1993, 98, 5648-5652; (b) C. T. Lee, W. T. Yang and R. G. Parr, Phys. Rev. B: Condens. Matter Mater. Phys., 1988, 37, 785-789; (c) M. J. Frisch, G. W. Trucks, H. B. Schlegel, G. E. Scuseria, M. A. Robb, J. R. Cheeseman, J. A. Montgomery, T. Vreven Jr, K. N. Kudin, J. C. Burant, J. M. Millam, S. S. Iyengar, J. Tomasi, V. Barone, B. Mennucci, M. Cossi, G. Scalmani, N. Rega, G. A. Petersson, H. Nakatsuji, M. Hada, M. Ehara, K. Toyota, R. Fukuda, J. Hasegawa, M. Ishida, T. Nakajima, Y. Honda, O. Kitao, H. Nakai, M. Klene, X. Li, J. E. Knox, H. P. Hratchian, J. B. Cross, V. Bakken, C. Adamo, J. Jaramillo, R. Gomperts, R. E. Stratmann, O. Yazyev, A. J. Austin, R. Cammi, C. Pomelli, J. W. Ochterski, P. Y. Ayala, K. Morokuma, G. A. Voth, P. Salvador, J. J. Dannenberg, V. G. Zakrzewski, S. Dapprich, A. D. Daniels, M. C. Strain, O. Farkas, D. K. Malick, A. D. Rabuck, K. Raghavachari, J. B. Foresman, J. V. Ortiz, Q. Cui, A. G. Baboul, S. Clifford, J. Cioslowski, B. B. Stefanov, G. Liu, A. Liashenko, P. Piskorz, I. Komaromi, R. L. Martin, D. J. Fox, T. Keith, M. A. AlLaham, C. Y. Peng, A. Nanayakkara, M. Challacombe, P. M. W. Gill, B. Johnson, W. Chen, W. M. Wong, C. Gonzalez and J. A. Pople, Gaussian 09 revision B.01, Gaussian, Inc., Wallingford CT, 2009; (d) N. M. O'Boyle, A. L. Tenderholt and K. M. Langner, J. Comput. Chem., 2008, 29, 839-845.

14 Y. Zhao, L. Wang, N. N. Fan, M. L. Han, G. P. Yang and L. F. Ma, Cryst. Growth Des., 2018, 18, 7114-7121.

15 (a) J. Z. Gu, Y. Cai, M. Wen, Z. F. Shi and A. M. Kirillov, Dalton Trans., 2018, 47, 14327-14339; (b) Q. G. Shang, T. Y. Zeng, K. Gao, N. N. Liu, Q. R. Cheng, G. Y. Liao, Z. Q. Pan and H. Zhou, New J. Chem., 2019, 43, 16595-16603.

16 (a) M. R. Hoffmann, S. T. Martin, W. Choi and D. W. Bahnemannt, Chem. Rev., 1995, 95, 69-96; (b) X. Meng, C. B. Fan, C. Bi, Z. A. Zong, X. Zhang and Y. Fan, CrystEngComm, 2016, 18, 2901-2912.
17 (a) Q. Ding, Y. Pan, Y. Luo, M. Zhou, Y. Guan, B. Li, M. Trivedi, A. Kumar and J. Liu, ACS Omega, 2019, 4, 10775-10783; (b) L. Lu, J. R. He, J. Wang, W. P. Wu, B. Li, A. Singh, A. Kumar and X. Qin, J. Mol. Struct., 2019, 1179, 612-617; (c) S. L. Cai, L. Lu, W. P. Wu, J. Wang, Y. C. Sun, A. Q. Ma, A. Singh and A. Kumar, Inorg. Chim. Acta, 2019, 484, 291-296; (d) E. H. Zhou, B. H. Li, W. X. Chen, Z. Luo, J. Liu, A. Singh, A. Kumar and J. C. Jin, J. Mol. Struct., 2017, 1149, 352-356; (e) Y. F. Yu, Z. Zong, C. B. Fan, X. M. Meng, X. Zhang and Y. H. Fan, Inorg. Nano-Met. Chem., 2019, 49, 455-460; (f) M. Zheng, Q. F. Han, X. M. Jia and J. W. Zhu, Mater. Sci. Semicond. Process., 2019, 101, 183-190; (g) P. D. Liu, H. J. Sun, X. F. Liu, H. T. Sui, Y. Zhang, D. G. Zhou, Q. H. Guo and Y. Ruan, J. Am. Ceram. Soc., 2017, 100, 3540-3549; (h) W. P. Wu, Q. J. Ding, X. R. Wu, Y. J. Huang, C. H. Gong, H. Huang, M. Trivedi and A. Kumar, Bull. Chem. Soc. Ethiop., 2019, 33(1), 51-60; (i) H. Wang, X. Y. Zhang, C. F. bi, Y. H. Fan and X. M. Meng, Transition Met. Chem., 2015, 40, 769-777; (j) J. M. Wang and Y. Zhao, Inorg. Nano-Met. Chem., 2017, 47, 69-72; (k) Z. A. Zong, C. F. Bi, Z. Zhu, C. B. Fan, X. M. Meng, X. Zhang and Y. H. Fan, New J. Chem., 2018, 42, 8905-8913; (l) Z. Zong, C. Bi, Z. Zhu, C. Fan, X. Meng, X. Zhang and Y. Fan, New J. Chem., 2018, 42, 8905-8913.

18 B. Yu, F. F. Wang, W. B. Dong, J. Hou, P. C. Lu and J. B. Gong, Mater. Lett., 2015, 156, 50-53.

19 J. Q. Liu, Y. Pan, Q. Ding, H. Xu, C. Shi, A. Singh and A. Kumar, CrystEngComm, 2019, 21, 4578-4585.

20 (a) F. Yuan, C. M. Yuan, C. S. Zhou, C. F. Qiao, L. Lu, A. Q. Ma, A. Singh and A. Kumar, CrystEngComm, 2019, 21, 6558-6565; (b) Q. Xia, X. Yu, H. Zhao, S. Wang, H. Wang, Z. Guo and H. Xing, Cryst. Growth Des., 2017, 17, 4189-4195.

21 J. P. Dong, Z. Z. Shi, B. Li and L. Y. Wang, Dalton Trans., 2019, 48, 17626-17632.

22 (a) C. Racles, M. F. Zaltariov, M. Iacob, M. Silion, M. Avadanei and A. Bargan, Appl. Catal., B, 2017, 205, 7892; (b) B. Civalleri, F. Napoli, Y. Noel, C. Roetti and R. Dovesi, CrystEngComm, 2006, 8, 364-371.

23 C. C. Wang, J. R. Li, X. L. Lv, Y. Q. Zhang and G. Guo, Energy Environ. Sci., 2014, 7, 2831-2867. 